\title{
Efecto de la bacteria Bacillus subtilis y el hongo Mic omizico Arbuscular Glomus fasc ic ulatum en la fertilización fosfórica en el cultivo de la papa (Solanum tuberosum ssp. andigena)
}

\section{Gladys Main'1 y Javier Franc o ${ }^{1}$}

\section{Resumen}

En Cochabamba, Bolivia, a una altitud de $3420 \mathrm{msnm}$, se estableció un ensayo con el cultivar de papa Waych'a (Solanum tuberosum ssp. andigena), para evaluar el efecto de la bacteria Bacillus subtilis y el hongo micorrizico Glomus fasciculatum en relación a una fertilización N-P-K con diferentes niveles de fósforo $(120 ; 60 ; 30 ; 00)$. Los tratamientos fueron distribuidos bajo un diseño de parcelas divididas en franjas con tres repeticiones. Entre las diversas variables evaluadas, $B$. subtilis con los niveles de fertilización 80-60-00 y 80-30-00 mostraron mayor emergencia $(72.37 \%)$ de plantas y mayor número de tallos (4), respectivamente, en comparación al testigo (sin bacteria y sin micorrizas). El tratamiento de $B$. subtilis con 80-30-00 de NPK presentó el mayor rendimiento (15940 $\mathrm{kg} / \mathrm{ha}$ ) y fue similar al testigo con el nivel comercial 80-12000 de NPK (15550 kg/ha). B. subtilis, superó en rendimiento (8598 kg/ha) al tratamiento con B. subtilis + G. fasciculatum, G. fasciculatum y al testigo absoluto (6306, 5508, 5585 $\mathrm{kg} / \mathrm{ha}$, respectivamente. La bacteria en presencia de incrementos de fósforo disminuyó su efectividad, por la presencia de hongos micorrizicos nativos en el suelo, G. fasciculatum, no mostró un efecto notorio sobre el rendimiento, pero a medida que se incrementó el fósforo, la frecuencia de $G$. fasciculatum en las raíces de papa disminuyó. Los tratamientos con $G$. fasciculatum, $B$. subtilis + G. fasciculatum presentaron menor daño de $R$. solani. Además se determinó un mejor aprovechamiento de fósforo por las plantas con G. fasciculatum y B. subtilis en

\footnotetext{
${ }^{1}$ Fundación para la Promoción e Investigación de Productos Andinos(Fundación PROINPA) Cochabamba, Bolivia, E-Mail: g.main@proinpa.org (Fundación PROINPA)
} 
combinación con los niveles 80-30-00 y 80-60-00 de fertilización NPK respectivamente, en comparación al testigo con 80-120-00 de NPK, lo que indica que altas aplicaciones de fósforo no son requeridas, permitiendo reducir los costos de fertilización y los riesgos ambientales. Por el mayor beneficio neto y menor costo variable el mejor tratamiento fue a $B$. subtilis con el nivel de fertilización 80-30-00 (kg/ha de NPK), con un retorno marginal de siete Bolivianos por cada Boliviano invertido.

Palabras claves adicionales:

Glomus, Bacillus, Rhizoctonia solani,

Aceptado para publicación: Diciembre 9, 2011

Effect of Bacteria Bac illus subtilis and the Arbusc ular Myc onhizal Fungi Glomus fasc ic ulatum in Phosphorus Fertilization in the Potato Crop (Solanum tuberosum ssp. andigena)

\section{Summary}

A field trial was established with Waych'a potato cultivar (Solanum tuberosum ssp. andigena) In Cochabamba, Bolivia at an altitude of $\mathbf{3 4 2 0}$ masl, to evaluate the effect of the bacteria Bacillus subtilis and mycorrhizal fungi Glomus fasciculatum in relation to NPK fertilization with different levels of phosphorus $(120,60,30,00)$. The treatments were distributed under a split plot design with three replications in strips. Among the different variables evaluated, $B$. subtilis with levels 80-60-00 and 80-30-00 fertilizer showed higher plants emergence (72.37\%) and more stems (4), respectively, compared to control. B. subtilis with 80-30-00 of NPK showed the highest yield $(15,940 \mathrm{~kg} / \mathrm{ha})$ and similar to the control with commercially 80-120-00 of NPK (15 550 $\mathrm{kg} / \mathrm{ha})$. B. subtilis, overcome (8598 $\mathrm{kg} / \mathrm{ha})$ to $B$. subtilis + G. fasciculatum, G. fasciculatum and absolute control $(6306,5508,5585 \mathrm{~kg} / \mathrm{ha}$, respectively. Bacterium in the 
presence of more phosphorus declined its effectiveness. Due to the presence of arbuscular mycorrhizal fungi $G$. fasciculatum showed no apparent effect on yield, but as increased phosphorus their frequency decreased. Treatments with G. fasciculatum, G. fasciculatum $+B$. subtilis showed less damage by $R$. solani. It was also found a better use of phosphorus by plants with $\mathrm{G}$. fasciculatum and $B$. subtilis in combination with $80-30-00$ and 80-60-00 levels compared to control, what indicates that high phosphorus applications are not required, allowing reducing fertilizer costs and environmental risks. For the greatest net benefit and lower cost variable the best treatment was $B$. subtilis with the level of 80-30-00 fertilizer (kg I ha), with a marginal return of seven bolivianos per boliviano invested.

Additional key words:

Glomus, Bacillus. Rhizoctonia solani.

\section{Introducción}

La papa (Solanum tuberosum) es uno de los cultivos de mayor importancia social y económica en la región andina. La producción en esta región es baja debido a factores abióticos y bióticos limitantes. El uso de agroquímicos en la agricultura demanda grandes inversiones y aún cuando estos no siempre han estado al alcance de los pequeños agricultores andinos, su uso indiscriminado e inadecuado para obtener resultados inmediatos, a largo plazo ha venido causando contrariamente al efecto esperado, daños considerables al medio ambiente y la salud de la población en general (Crissman et al., 1998). Los microorganismos del suelo son los mejores aliados para lograr un buen crecimiento y nutrición de las plantas, formando una serie de asociaciones simbióticas y no simbióticas para un mejor aprovechamiento de los recursos del suelo. Entre estas asociaciones se encuentran los microorganismos que ayudan a la degradación de la materia orgánica, la fijación de nitrógeno, producción y liberación de sustancias reguladoras del crecimiento vegetal, solubilización de elementos minerales y 
protección frente a fitopatógenos, entre otros. Es así que desde hace algunos años se viene investigando el empleo de microorganismos que promuevan un mejor desarrollo de las plantas y en lo posible un efecto supresor de enfermedades (Fitter y Garbaye, 1994).

La bacteria $B$. subtilis es enemigo natural de muchas enfermedades de plantas, tales como las que pertenecen a los géneros Rhizoctonia, Pythium. Phytophthora, Fusarium, Rhizopus, Mucor, Oidium, Botrytis, Colletotrichum, Erwinia, Pseudomonas, Xanthomonas y muchas otras más; además puede reducir la incidencia de nematodos (Kapulnik, 1996). Además dentro del manejo de microorganismos naturales, se tienen los inoculantes fúngicos que una vez introducidos en el suelo, éstos se establecen y producen un beneficio sobre las plantas. El mecanismo por el cual estos inoculantes se pueden establecer en el suelo es por el desplazamiento a algunos miembros de la comunidad pre-existente, y para ello es necesario contar con especies agresivas, las cuales deben ser incorporadas por diferentes métodos en concentraciones altas $\left(10^{8} / \mathrm{g}\right.$ o $\mathrm{ml}$ de unidades formadoras de colonias) y de acuerdo con el tipo de cultivo, las prácticas de siembra y la fertilidad del suelo (Jacobsen, 1995).

Es así mismo conocido que estos hongos micorrizicos aumentan significativamente la capacidad de absorción de fósforo $(P)$ de las plantas inoculadas, ya que forman una cubierta sobre la raíz extendiendo su micelio a varios metros de la planta. Estudios realizados muestran que el uso de inoculantes en base a micorrizas aumentan significativamente la producción en campo y disminuyen la necesidad de fertilización con $\mathrm{P}$ en cultivos de trigo, papa, soja pimiento y caña de azúcar (Adholeya et al., 2005).

Además de este efecto nutricional, las micorrizas arbusculares juegan un rol clave en la sostenibilidad del sistema suelo-planta, ya que incrementan el número de microorganismos benéficos en la rizósfera, creando una ambiente de micorrizas favorable para el desarrollo de poblaciones nativas. Estas poblaciones están conformadas por bacterias simbiontes fijadoras de 
Nitrógeno, microorganismos que solubilizan el $\mathrm{P}$, bacterias promotoras de crecimiento tales como Pseudomonas y Bacillus, así como otros organismos de vida libre (Linderman, 1992). Estas poblaciones nativas, así como la red de hifas de las micorrizas, mejoran la calidad de los suelos agrícolas al formar agregados estables que favorecen la aireación y la percolación del agua debido a la producción de glomalina (Rosier et al., 2006). De estos estudios, se conoce que la clave en la formulación de un inoculante es combinar microorganismos rizosféricos seleccionados (micorrizas, hongos saprobios, bacterias) que al realizar diferentes procesos en el suelo permitan reducir la aplicación de fertilizantes químicos y maximicen el crecimiento y nutrición de las plantas (Toro et al., 1998).

Por todo lo indicado, la combinación de hongos micorrizicos arbusculares (AMF), tal como $G$. fasciculatum y la bacteria $B$. subtilis, podrían constituir una alternativa para reducirse el empleo de fertilizantes sintéticos, mejorar la calidad de los suelos y la sanidad de las cosechas. En este contexto, el presente estudio tiene por objetivo evaluar el efecto de la inoculación de bacteria y hongo micorrízico sobre la sanidad y el comportamiento agronómico del cultivar de papa Waych'a fertilizado con diferentes niveles de fósforo.

\section{Materiales y Métodos}

En instalaciones del Centro Toralapa, ubicado a $72 \mathrm{~km}$ de la ciudad de Cochabamba, a una altitud de $3420 \mathrm{msnm}$, entre las coordenadas de $65^{\circ} 61^{\prime}$ de longitud oeste y $17^{\circ} 25^{\prime}$ de latitud sur, se estableció el ensayo con el cultivar nativo W'aycha (Solanum tuberosum ssp andigena). El clima de este lugar es de estepa montano sub-húmedo. La temperatura mínima en los meses del ciclo del cultivo fue de $5^{\circ} \mathrm{C}$ y la temperatura máxima fue $20^{\circ} \mathrm{C}$, la precipitación alcanzó a $605 \mathrm{~mm}$. El suelo dónde se realizó el ensayo es de tipo franco limoso con un pH 4.35, N: 24 ppm, P: 21 ppm y K: 256 ppm con $1.6 \%$ de materia orgánica. 
Los microorganismos evaluados fueron Bacillus subtilis $y$ Glomus fasciculatum en combinación con diferentes niveles de fertilización de N-P-K (80-120-00; 80-60-00; 80-30-00; 80-00-00 y 00-00-00) y un testigo absoluto sin ninguna aplicación. Los 20 tratamientos resultantes fueron distribuidos de acuerdo a un diseño de parcelas divididas en franjas y con tres repeticiones El tamaño de la unidad experimental fue de $7.2 \mathrm{~m}^{2}$.

Al momento de la siembra se realizó aplicaciones con mochila sobre el tubérculo de papa y el estiércol de vacuno aplicado a la parcela a una relación de $10 \mathrm{t} / \mathrm{ha}$ con el hongo micorrizico Glomus fasciculatum en una formulación comercial (DESAMIC, con 15 esporas/ gramo de producto) a la dosis de $375 \mathrm{~g} / 5 \mathrm{~L}$ (15 $\mathrm{kg} / \mathrm{ha}$ ) y la bacteria Bacillus subtilis en una formulación comercial (FZB 24 WG, $5.8 \times 10^{6}$ unidades formadoras de colonias (ufc) a una dosis de $12.5 \mathrm{~g} / 5 \mathrm{~L}$ ( $250 \mathrm{~g} / \mathrm{ha}$ )

Las variables agronómicas evaluadas fueron: emergencia (\%), altura de planta $(\mathrm{cm})$, número de tallos, materia seca $(\%)$, volumen de raíz y rendimiento e índice de efectividad (I.E.)de tratamientos que se determinó en base a la siguiente fórmula:

I.E. $(\%)=[($ Rendimiento tratamiento - Rendimiento testigo $) /$ Rendimiento testigo] * 100

También se evaluaron variables microbiológicas tales como: potencial de multiplicación del hongo $G$. fasciculatum en raíces (Vierheiling et al. 1998), número de esporas del mismo en suelo (Sieverding, 1991), evaluación del potencial de multiplicación de la bacteria $B$. subtilis (Ernst, 2005) e incidencia de Rhizoctonia solani de acuerdo a la siguiente escala (CIP, 1983): 0 (sano); 1 (0.1- $5 \%$ de esclerotes sobre tubérculos); 2 (5.1- 25\% de esclerotes sobre tubérculos); 3 (> $25 \%$ de esclerotes sobre tubérculos).

La emergencia de plantas, número de tallos, materia seca del follaje, materia seca de raíces, materia seca de tubérculos de papa, volumen de raíz, rendimiento por categorías $(\mathrm{kg} / \mathrm{ha})$, y contenido de fósforo en suelo fueron procesados con el modelo lineal mixto (Montgomery, 2003;); el número de tubérculos por planta y esporas de micorrizas en suelo con el modelo lineal 
generalizado mixto, bajo la distribución de Poisson y Binomial, respectivamente; la presencia de Rhizoctonia con el modelo lineal generalizado bajo el supuesto de distribución Multinomial. Estas variables fueron analizadas bajo el criterio del análisis de varianza correspondiente al diseño bloques al azar con arreglo en parcelas divididas en franjas.

La discriminación de los tratamientos fueron realizados con la sentencia de Lsmeans (promedios por mínimos cuadrados) y la distribución de $\mathrm{t}$ de Student para el modelo lineal mixto y modelo lineal generalizado mixto (SAS Institute Inc, 2004).

Por otra parte se realizó correlaciones de Pearson del rendimiento de papa (T/ha) con las variables número de tubérculos/planta, altura de planta $(\mathrm{cm})$, número de tallos/planta, volumen radicular, materia seca follaje (\%), materia seca raíz (\%) y materia seca de tubérculos (\%) por microorganismos y niveles de fertilización.

El análisis económico se realizó mediante la metodología de presupuestos parciales propuesta por CIMMYT (1988), considerándose como costos variables a los tratamientos y mano de obra.

\section{Resultados y Disc usión}

A continuación se presentan los resultados de las diversas evaluaciones realizadas durante el desarrollo y cosecha del cultivo de papa.

I. Evaluaciones agronómicas del cultivo de papa. Los análisis de varianza y la discriminación de medias, de las diversas variables agronómicas relacionadas con el desarrollo de las plantas y el rendimiento del cv. Waych'a (Solanum tuberosum ssp. andigena), se presentan de forma resumida en las Tablas 1,2 y 3. 
La Tabla 1 muestra los valores de significación para las variables emergencia, número de tallos y altura de planta en el cultivar Waych'a.

La emergencia de plantas fue mayor y altamente significativa para la aplicación del nivel 80-30-00 y no así para B. subtilis, G. fasciculatum, B. subtilis+G. fasciculatum, testigo y la interacción microorganismo $x$ fertilización; esto último probablemente se deba a que estos microorganismos fueron afectados por características del sustrato, valores altos de fósforo y $\mathrm{pH}$ variable (Moreno, 1988). Con respecto al número de tallos, no se observaron diferencias estadísticas entre los efectos simples o sus interacciones. Por el contario la variable altura de planta mostró diferencias altamente significativas tanto para los microorganismos, como para los niveles de fertilización y su interacción, Las mayores alturas de planta se observó con $B$. subtilis y 80-120-00; también con G. fasciculatum y 80-120-00.

Los valores para las variables materia seca de follaje, raíces, tubérculos y volumen de raíces del cultivar Waych'a se presentan en la Tabla 2. Respecto a la variable materia seca de follaje, no se observaron diferencias estadísticas para microorganismos y fertilización y probablemente se deba a las condiciones climáticas y de suelo que no permitieron mostrar el efecto de los fertilizantes y los microorganismo, ya que la papa responde de forma variable (Moreno, 1988).

La variable materia seca de raíz y tubérculos tampoco mostraron diferencias estadísticas para microorganismo y fertilización, probablemente por el pH del suelo o las condiciones climáticas (Moreno, 1988; Coyne, 2000).

Respecto al volumen de raíz de papa, no se observaron diferencias estadísticas entre los microorganismos y la combinación microorganismo x fertilización, sin embargo si se presentaron diferencias ( $P$ : 0.01) para los niveles de fertilización. El mayor volumen de raíz (cc) del cv Waych'a se dio con la aplicación de 80-30-00, lo cual le habría favorecido una mayor absorción de nutrientes y agua del suelo (Toro et al., 1998). 
Tabla 1. Significancias para las variables emergencia, número de tallos y altura de planta en el cultivar Waych'a

\begin{tabular}{|l|c|c|c|}
\hline \multicolumn{1}{|c|}{ Fuentes de variación } & $\begin{array}{c}\text { Emergencia de } \\
\text { plantas de papa }\end{array}$ & No de tallos & Altura de planta \\
\hline Evaluación & & & $\mathrm{ns}$ \\
\hline Microorganismo & $\mathrm{ns}$ & $\mathrm{ns}$ & $\mathrm{ns}$ \\
\hline Evaluación x Microorganismo & & $\mathrm{ns}$ & $\star \star$ \\
\hline Fertilización & $\star \star$ & & $\mathrm{ns}$ \\
\hline Evaluación x Fertilización & & $\mathrm{ns}$ & $\star \star$ \\
\hline Microorganismo x Fertilización & $\mathrm{ns}$ & $\mathrm{ns}$ \\
\hline Evaluación x Microorganismo x Fertilización & & & \\
\hline
\end{tabular}

Tabla 2. Significancias para materia seca de follaje, raíces, tubérculos y volumen de raíces del cultivar Waych'a

\begin{tabular}{|l|c|c|c|c|}
\hline \multicolumn{1}{|c|}{ Fuentes de variación } & $\begin{array}{c}\text { Materia seca de } \\
\text { follaje }\end{array}$ & $\begin{array}{c}\text { Materia seca } \\
\text { de raíz }\end{array}$ & $\begin{array}{c}\text { Materia seca de } \\
\text { tubérculos }\end{array}$ & Volumen de raíz \\
\hline Microorganismo & $\mathrm{Ns}$ & $\mathrm{ns}$ & $\mathrm{ns}$ & $\mathrm{ns}$ \\
\hline Fertilización & $\mathrm{Ns}$ & $\mathrm{ns}$ & $\mathrm{ns}$ & $\mathrm{n}$ \\
\hline Microorganismo $x$ Fertilización & $\mathrm{Ns}$ & $\mathrm{ns}$ & $\mathrm{ns}$ & $\mathrm{ns}$ \\
\hline
\end{tabular}

ns: No Significativo a P: $0.05 /$ **: Significativo a P: 0.01 
Tabla 3. Significancias para cantidad de tubérculos (\%), número de tubérculos totales/planta y rendimiento $(\mathrm{kg} / \mathrm{ha})$ del cultivo de papa

\begin{tabular}{|l|c|c|c|c|}
\hline \multicolumn{1}{|c|}{ Fuentes de variación } & $\begin{array}{c}\text { Cantidad de } \\
\text { tubérculos (\%) }\end{array}$ & $\begin{array}{c}\text { Número de tubérculos } \\
\text { totales/planta }\end{array}$ & $\begin{array}{c}\text { Rendimiento por } \\
\text { categoría (kg/ha) }\end{array}$ & $\begin{array}{c}\text { Rendimiento } \\
\text { total (kg/ha) }\end{array}$ \\
\hline Microorganismo & $\star *$ & $\mathrm{~ns}$ & $\mathrm{~ns}$ & $\mathrm{~ns}$ \\
\hline Fertilización & $\star$ & $\star *$ & $\mathrm{~ns}$ & \\
\hline Microorganismo x Fertilización & $\star *$ & $\mathrm{~ns}$ & $\star \star *$ \\
\hline $\begin{array}{l}\text { Tamaño (Microorganismo * } \\
\text { Fertilización) }\end{array}$ & - & - & $\mathrm{ns}$ \\
\hline
\end{tabular}

ns: No Significativo a P: 0.05

**: Significativo a P: 0.01

*: Significativo a P: 0.05 
Finalmente entre las variables agronómicas se presentan en la tabla 3 los valores de significancias correspondientes a los rendimientos. Respecto al rendimiento, se obtuvieron diferencias ( $P$ : 0.01) para los niveles de fertilización y no así para los microorganismos y la interacción microorganismos $\mathrm{x}$ fertilización. La Figura 1 muestra que el tratamiento $B$. subtilis en combinación con una fertilización de 80-30-00 presenta el mayor rendimiento $(15940 \mathrm{~kg} / \mathrm{ha})$ en comparación al testigo que alcanza similar rendimiento pero con el nivel 80-120-00 (15550 $\mathrm{kg} / \mathrm{ha}$ ) lo que confirma que las bacterias promotoras de crecimiento aumenta el vigor de la planta (Cobarrubias-Ramirez et al., 2005), probablemente porque $B$. subtilis aumentó la disponibilidad de fósforo del suelo (Benizri et al., 2001) o fue capaz de alterar la permeabilidad de las células facilitando la absorción de iones (Kapulnik, 1996), constituyendo así $B$. subtilis una alternativa para reducir costos en la aplicación de fosforo y el daño al medio ambiente (Toro et al., 1998). Por otra parte los rendimientos de papa obtenidos con la aplicación de microorganismos superan a los reportados a nivel nacional de 7 T/ha (Zeballos, 2006).

Estimada la efectividad de los microorganismo en relación con los rendimientos (Sieverding, 1999) se determinó que con la aplicación de $B$. subtilis (Tabla 4), se obtiene un incremento del rendimiento en un $53.97 \%$ y aplicando $B$. subtilis en presencia de 80-00-00, 80-30-00 y 80-60-00 también se obtiene efectividad entre $38.59 \%$ a $3.82 \%$, es decir la bacteria en presencia de incrementos de fósforo con nitrógeno (80 kg/ha) disminuye la efectividad (Cobarrubias-Ramírez et al., 2005). Es de notar que $B$. subtilis $+G$. fasciculatum presentan efectividad con la fertilización 80-00-00, seguida de la ausencia de fertilización. En resumen hay mayor efectividad con la bacteria $B$. subtilis y no con $G$. fasciculatum, probablemente porque éste último es afectado por las condiciones edafo-climáticas y la fertilización fosfatada, que suprimía considerablemente la colonización en plantas inoculadas con G. fasciculatum (Black y Tinker, 1977) y el factor competitivo de la población de endófitos nativos (Moreno, 1988). 


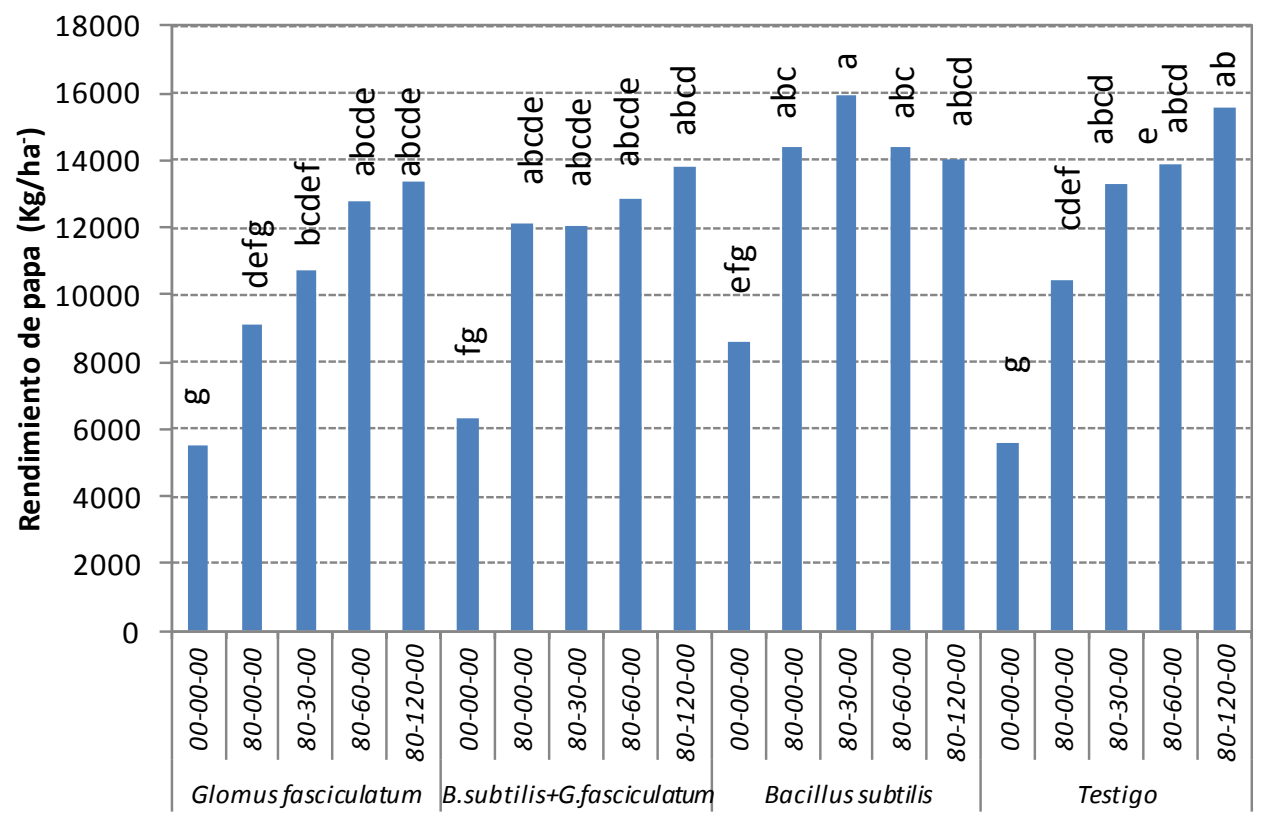

Fertilización y tratamientos

Figura 1. Efecto de la aplicación de $G$. fasciculatum, B. subtilis y la combinación de ambos con diferentes niveles de fósforo en el rendimiento de papa Waych'a (kg/ha)

Tabla 4. Efecto de la aplicación de G. fasciculatum, B. subtilis y la combinación de ambos, con diferentes niveles de fósforo en el índice de efectividad (\%)

\begin{tabular}{|c|c|c|c|}
\hline Fertilización & \multicolumn{3}{|c|}{ Microorganismos } \\
\hline (kg/ha) & G. fasciculatum & $\begin{array}{c}\text { B.subtilis + } \\
\text { G. fasciculatum }\end{array}$ & B.subtilis \\
\hline $00-00-00$ & -1.37 & 12.92 & 53.97 \\
\hline $80-00-00$ & -12.18 & 16.86 & 38.59 \\
\hline $80-30-00$ & -19.07 & -9.40 & 20.00 \\
\hline $80-60-00$ & -7.74 & -7.60 & 3.82 \\
\hline $80-120-00$ & -14.22 & -11.27 & -10.04 \\
\hline
\end{tabular}


Se determinó que el rendimiento de papa está altamente correlacionado (P: 0.01) con la altura de planta, con el volumen radicular y el número de tallos /planta. El testigo (sin microorganismo) con 80-30-00 presentó correlaciones del rendimiento con 3 variables (altura de planta, número de tallos y volumen radicular), indicando que estas a medida que aumentan sus valores el rendimiento también aumenta. Así mismo, el tratamiento $B$. subtilis con $80-60-00$ presentó correlación con el número de tubérculos y altura de planta; entre tanto en el tratamiento $B$. subtilis con 80-30-00, el rendimiento estuvo correlacionado con la altura de plata y volumen radicular; Esto implicaría que a incrementos de las variables altura de planta, volumen radicular, número de tallos/planta, también ocurren incrementos en el rendimiento.

II. Evaluación de microorganismos. Las bacterias evaluadas en el suelo presentaron significación estadística (P: 0.05) para la interacción de microorganismo x fertilización, es decir que los diferentes microorganismos y niveles de fertilización tienen efectos dependientes sobre las bacterias en el suelo (Tabla 5).

También se destaca el microorganismo $B$. subtilis en combinación con la fertilización 80-30-00, B. subtilis + $G$. fasciculatum en combinación con la fertilización 80-120-00 y sin fertilización por las mayores magnitudes de unidades formadoras de colonias y se diferencian de los tratamientos B.subtilis $+G$. fasciculatum con 80-30-00 y testigo con 80-00-00 y 80-60-00, que presentaron bajas cantidades de colonias, los otros tratamientos no mencionados son intermedios probablemente esto se deba a que los fertilizantes químicos alteran el ecosistema biológico, ejerciendo una presión negativa sobre los microorganismos del suelo lo cual podría tener efecto en el desarrollo de los cultivos (Tanu y Adholeya, 2006).

Respecto al número de colonias, las evaluaciones realizadas indican que en forma general Bacillus está presente en el suelo, pero en los tratamientos donde se inoculó $B$. subtilis existió mayor multiplicación 68 días después de la siembra (dds) con la fertilización 80-00-00 y 80-30-00), lo cual permite minimizar el uso de químicos en comparación a la aplicación de $B$. subtilis 
con 80-120-00. Por otra parte, G. fasciculatum favoreció la multiplicación de la bacteria en comparación al testigo. Así mismo se observan las diferentes fases de crecimiento microbiano como es la latencia, exponencial, estabilización o meseta y muerte o esporulación total de acuerdo a las fases fenológicas de la planta (Furrazola et al., 1990).

Rhizoctonia solani en tubérculos presentó diferencias estadísticas para microorganismos, fertilización y la interacción de las mismas (P: 0.05). En general, los microorganismos $G$. fasciculatum, $B$. subtilis $+G$. fasciculatum presentaron menor daño de $R$. solani en comparación a la aplicación de sólo $B$. subtilis, tal como señala Sánchez (1999), que indica que las micorrizas arbusculares incrementan la resistencia de la planta al ataque de los patógenos, en especial a los que atacan la raíz.

III. Evaluación económica. Los resultados del análisis de costos por presupuestos parciales (Figura 2), en base a los rendimientos obtenidos como respuesta a la aplicación de microorganismos y diversos niveles de fertilización, se tiene que el mejor tratamiento corresponde a $B$. subtilis más la fertilización con 80-30-00 (kg/ha) por el mayor beneficio neto y menor costo variable; éste tratamiento presentó un retorno marginal de $7 \mathrm{Bs}$ adicionales por cada Bs invertido respecto al tratamiento con $B$. subtilis más 80-00-00. Estos resultados no sólo tienen importancia económica sino también ambiental ya que el uso indiscriminado de fertilizantes químicos altera la microbiología del suelo (Tanu y Adholeya, 2006). Además Bacillus tiene la habilidad de degradar compuestos químicos orgánicos como los pesticidas. 
Tabla 5. Cuadro de significancias para las variables bacterias (ufc), frecuencia de micorrización (\%), intensidad de micorrización (\%), micorriza en el suelo, fósforo y presencia de Rhizoctonia solani

\begin{tabular}{|c|c|c|c|c|c|c|}
\hline Fuente variación & $\begin{array}{c}\text { Bacterias } \\
\text { (ufc) }\end{array}$ & $\begin{array}{l}\text { Frecuencia de } \\
\text { micorrización } \\
(\%)\end{array}$ & $\begin{array}{l}\text { Intensidad de } \\
\text { micorrización } \\
(\%)\end{array}$ & $\begin{array}{c}\text { Micorriza en } \\
\text { suelo (esporas I } \\
100 \text { g suelo) }\end{array}$ & $\begin{array}{l}\text { Fósforo en } \\
\text { suelo (ppm) }\end{array}$ & $\begin{array}{l}\text { Rhizoctonia } \\
\text { solani }\end{array}$ \\
\hline Evaluación & ns & $\star \star$ & ** & - & - & - \\
\hline Microorganismos & ns & ns & ns & ns & ns & * \\
\hline $\begin{array}{l}\text { Evaluación } \mathrm{x} \\
\text { Microorganismos }\end{array}$ & ns & ns & ns & - & - & - \\
\hline Fertilización & ns & ns & ns & ns & ** & * \\
\hline $\begin{array}{l}\text { Evaluación x } \\
\text { Fertilización }\end{array}$ & ns & ns & ns & - & - & - \\
\hline $\begin{array}{l}\text { Microorganismos x } \\
\text { Fertilización }\end{array}$ & * & ns & ns & ns & ns & * \\
\hline $\begin{array}{l}\text { Evaluación } x \\
\text { Microorganismos x } \\
\text { Fertilización }\end{array}$ & - & ns & ns & - & - & - \\
\hline
\end{tabular}

ns: No significativo a P: 0.05

**: Significativo a P: 0.01

*: Significativo a P: 0.05

ufc = Unidades formadoras de colonias 


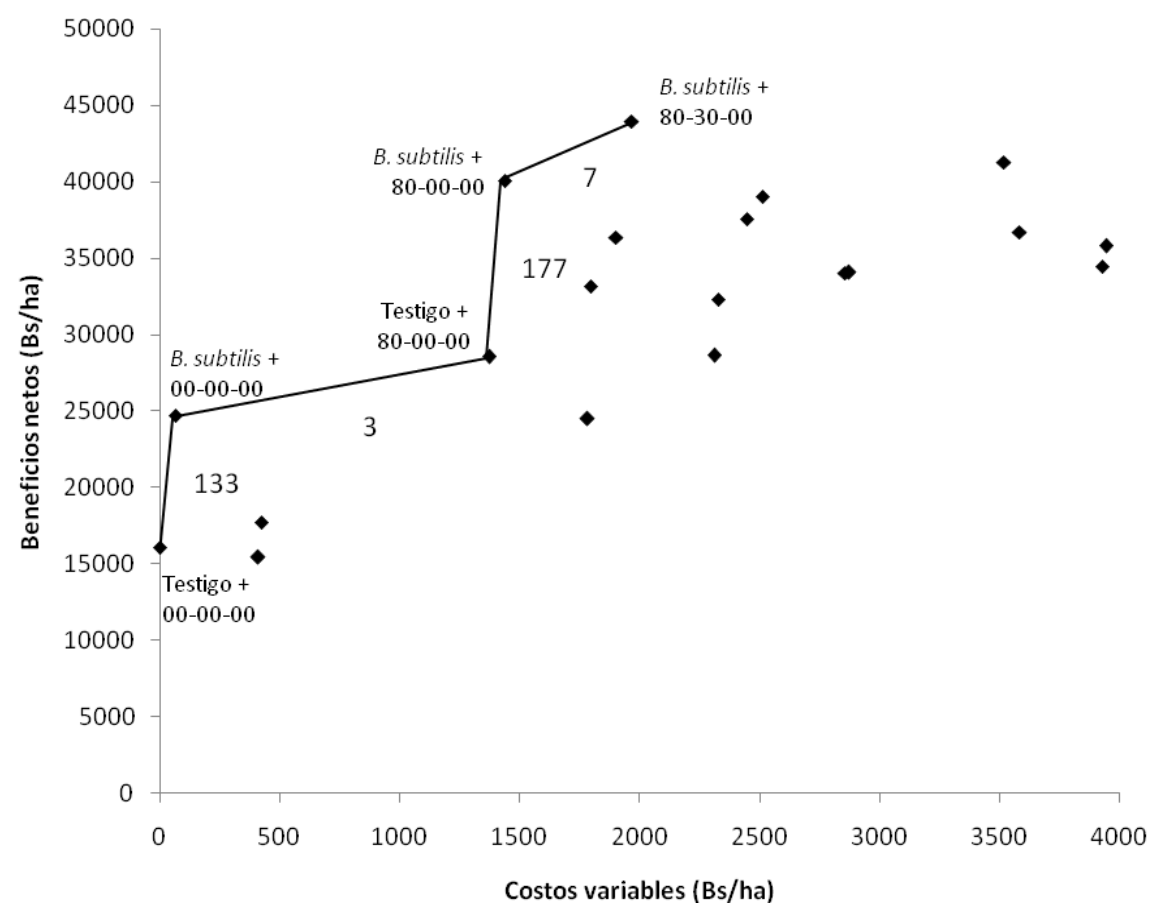

Figura 2. Curva de costos variables y beneficios netos de los tratamientos 


\section{Conclusiones}

De acuerdo a los objetivos planteados y resultados obtenidos en el estudio se lograron las siguientes conclusiones:

- El rendimiento de papa está altamente correlacionado (P: 0.01) con la altura de planta, el volumen radicular y el número de tallos/planta. El mayor rendimiento obtenido fue con la combinación $B$. subtilis y la fertilización 80-30$00(15940 \mathrm{~kg} / \mathrm{ha})$, similar al tratamiento sin microorganismos pero con 80-120-00 de fertilización $(15550 \mathrm{~kg} / \mathrm{ha})$, donde el primer tratamiento permite un ahorro de fosforo y reduce el daño al medio ambiente.

- Los tratamientos con G. fasciculatum, B. subtilis + G. fasciculatum al presentar menor daño de Rhizoctonia solani en tubérculos de papa Waych'a, confirmaron su efecto supresor.

- Probablemente debido a la presencia de micorrizas nativas en el suelo no se observó un efecto notorio de $G$. fasciculatum sobre el cultivo de papa, sin embargo a medida que los niveles de fósforo aumentaron, la frecuencia del aislamiento de $G$. fasciculatum fue menor.

- El tratamiento más eficiente correspondió a B. subtilis con la fertilización 80-30-00 (kg/ha) por el mayor beneficio neto y menor costo variable; este tratamiento proporcionó un retorno marginal de 7 Bs adicionales por cada 1 Bs invertido respecto al tratamiento con $B$. subtilis más 80-00-00 y los otros tratamientos, lo cual constituye una alternativa para mejorar la economía de los agricultores y reducir el daño al medio ambiente.

\section{Agradecimientos}

Agradecemos a la Comunidad Europea por el financiamiento y apoyo proporcionado durante la ejecución del presente estudio como parte del proyecto COMMINANDES (Sustainable potato production in Andean Urban and periurban areas by combining bio-composting and microbial inoculants - EEC Contract ICA4- 
CT2002-10016).Así mismo se agradece a los Ings. Gino Aguirre y Benigno Bascope de la Facultad de Ciencias Agrícolas y Pecuarias, Forestales y Veterinarias de la UMSS por su apoyo durante la ejecución de la tesis de MSc del primer autor y a la Cooperación Belga por el financiamiento brindado para la realización de la maestría de Protección Vegetal y Medio Ambiente.

\section{Referencias Bibliográfic as}

Adholeya, A. 2006. Potential of Arbuscular Mycorrhizae in Organic Farming Systems, En: Handbook of Microbial Biofertilizers. Eds Rai MK. Food Products Press. The Haworth Press, Inc. Londres.

Adholeya, A..P. Tiwari; R. Singh. 2005. Large scale inoculum production of arbuscular Mycorrhizal fungi. En in vitro culture of mycorrhizas. Eds: S. Declerk; D.G. Strullu. Springer, Alemania.

Black, R.L.B; P.B. Tinker. 1977. Interactions between effect of vesicular-arbuscular mycorrhiza and fertilizer phosphorus on yield of potato in the field. Nature. Lond. 265:510-511.

Benizri, E.; E.Baudoin; A.Guckert. 2001. Root colonization by inoculated plant growth-promoting rhizobacteria. Biocontrol Science and Technology, 11, 557-574.

Cobarrubias-Ramírez, J.; J. Castillo-Aguilar; Vera, Nuñez NuñezEscobar; P.Sanchez-Garcia;; R. Aveldaño-Salazar; J. Peña-Cabriales. 2005. Absorción y eficiencia de uso de Fósforo en papa cultivar alpha con 32P. Agrociencia 39: 127-136.

CIMMYT. 1988. La formulación de recomendaciones a partir de datos agronómicos: Un manual metodológico de evaluación económica. Edición complementada revisada. México D.F. México, CIMMYT.

CIP. 1983. Principales enfermedades, nematodos e insectos de la papa Apartado 5969 Lima, Perú 95 p.

Coyne, D. 2000. Microbiología del suelo: Un enfoque exploratorio Edit. ITP Paraninfo $415 \mathrm{pp}$. 
Crissman, C.; J. Antle; S. Capaibo. 1998. Economic, environmental and health tradeoffs in agriculture: pesticides and the sustainability of Andean potato production. Dordrech/Boston/London:Kluwer Academic Publishers, "Natural Resource Mnagement and Policy" Series, 281 p.

Ernst, C. 2005. Effet de l'inoculation d'une bactérie promotrice de croissance et d' un champignon mycorhizien á arbuscules sur la croissance de deux variétés de pomme de terre en sol pasteurisé et non-pasteurisé . Mémorie présemté em vue de l'obtention du grade de bio-ingénieur, Université Catholique de Louvain-la Neuve, 125 pp.

Fitter, A.H. ; J. Garbaye. 1994. Interaccions between micorrhizal fungi and others soil organism. Plant and Soil. 159, 123-132.

Furrazola, E.; F. Fernandez; M.O. Orosco. 1990. Variaciones de las poblaciones de hongos micorrizogenos VA asociados a distintos estadios fenológicos en dos campos de soya. Memorias VII Seminario Científico INCA. Vol I. p. 157-166.

La siguiente referencia puede ser útil para explicar otros posibles efectos de B.subtilis Gnanamanickam, S.S.(ed.). 2006. Plantassociated bacteria. Springer. The Netherlands. 712 p.

Jacobsen, I. 1995. Transport of phosphorus and Carbon in VA mycorrizas En: Varma, A. y Hock B. (edit. ) Micorrhiza: Structure, function, molecular biology and biotechnology. Springer-Berlag, Berlin pp 297-324.

Kapulnik, Y. 1996. Plant growth promotion by rhizosphere bacteria. In: Waisel, Y, ; Eshel A, Kafkafi, U, (eds.). Plant roots The hidden half. New York, USA, Marcel Dekker, 769-781.

Moreno, P. 1988. Inoculación de micorrizas MVA en papa (Solanum tuberosum). Respuesta en el crecimiento y nutrición de plantas inoculadas en invernadero y en campo Revista Latinoamericana de la Papa 1, 84-103.

Rosier, C.L.; A.T. Hoye; M. Rilling. 2006. Glomalin-related solí protein: Assessment of current detection and quantifications tools. Soil Biol. Biochem. 38:2205-2211.

Sánchez, M. 1999. Endomicorrizas en agroecosistemas colombianos. Universidad Nacional de Colombia 227 pp. 
SAS Institute Inc. 2004. Documentation for SAS, Version 8. http://v8doc.sas.com/sashtml/

Sieverding, E. 1991. Vesicular Arbuscular Mycorrhiza in tropical agrosystem . Deutsche Gasellsschaft fur technische Zusammenarbeit (GTZ) GMBH, Federal Republic of Germany. 371 p.

Tanu, P.A. A. Adholeya. 2006. Potential of arbuscular mycorrhizae in organic farming systems, En: Handbook of microbial biofertilizers. Eds Rai MK. Food products Press. The Haworth Press, Inc. Londres.

Toro, M.,; Azcón; J.M. Barea. 1998. The use if isotopic dilution techniques to evaluate the interactive effects of Rhizobium genotypes, mycorrhiza fungi, phosphate solubilizing rhizobacteria and rock phosphate on nitrogen and phosphorus acquisition by Medicago sativa. New Phytol 138: 265-273.

Vierheilig, H.P.; Andrew, ; Urs Wyss Coughlan; Yves Piché. 1998. Ink and Vinegar, a Simple Staining Technique for Arbuscular-Mycorrhizal Fungi Applied and Environmental Microbiology, December 1998, p. 5004-5007, Vol. 64, No. 12.

Zeballos, H. 1997. Aspectos económicos de la producción de papa en Bolivia. COSUDE - Centro Internacional de la Papa (CIP). Lima, Perú. 